\title{
KEYNOTE ADDRESS: CONSERVATION GENETICS OF FRESHWATER ORGANISMS
}

\author{
S. WEISS
}

Karl-Franzens UniversitätGraz, InstitutfürZoologie, Universitätsplatz 2, A-8010Graz, Austria. E-Mail: steven.weiss@uni-graz.at

Reçu le 12 janvier 2005

Accepté le 21 avril 2005

Received on January 12, 2005

Accepted April 21, 2005

\begin{abstract}
This manuscript serves as a summary of both the importance of genetics in conservation, and the range of methodological approaches available. Two somewhat distinct realms of conservation genetics are outlined. The first theoretically rests upon the field of population genetics, and primarily concerns itself with the conservation of genetic diversity within and among populations, both in the wild and captivity. Basic concepts such as heterozygosity, genetic drift, and effective population size are discussed in the framework of freshwater conservation interests. Most importantly, it is emphasized that only multi-locus data sets, with adequate sample sizes are appropriate for answering a range of conservation-oriented questions with such population genetic approaches. The second area of research rests upon the fields of phylogenetics and phylogeography and concerns itself with systematics and the designation of conservation units. The somewhat popularised role of using trees based on mitochondrial DNA sequences and phylogeographic structure to define conservation units is described, but also criticized. In its place, a pluralistic approach should be undertaken, which takes into consideration both the socio-economic and legislative framework within which conservation units can be managed. Finally, despite much attention to the varying definition of conservation units, both theoretical and practical considerations support that the unit most important to conservation is the population.
\end{abstract}

Key-words: Central Europe, population genetics, phylogenetics, phylogeography, crayfish, salmonids.

\section{NOTE TECHNIQUE : GÉNÉTIQUE DE LA CONSERVATION DES ORGANISMES D'EAU DOUCE}

\section{RÉSUMÉ}

Cet article présente un résumé rapportant l'importance de la génétique pour la conservation et l'ensemble des approches méthodologiques disponibles. Deux domaines quelque peu distincts de la conservation génétique sont abordés. Le premier, en théorie, s'appuie sur la génétique des populations, et plus particulièrement sur la conservation de la diversité génétique dans et entre populations, dans la nature et en captivité. Les concepts de base comme le taux d'hétérozygotie, la dérive génétique et la taille efficace d'une population, sont discutés dans le cadre des objectifs de la conservation en eau douce. Avec de telles approches de génétique des populations, il est essentiel de souligner que seules des données multi-locus, sur des tailles d'échantillon adéquates sont adaptées pour répondre à l'ensemble des questions relevant de la conservation. Le second domaine de recherche s'appuie sur les domaines de la phylogénétique et de la phylogéographie 
et concerne la systématique et la désignation des unités de conservation. Le rôle des très populaires arbres basés sur les séquences de l'ADN mitochondrial est décrit mais également critiqué. En remplacement, une approche plurielle doit être entreprise prenant en considération et le cadre socio-économique et le cadre législatif à l'intérieur desquels les unités de conservation peuvent être gérées. Enfin, malgré l'attention portée aux diverses définitions des unités de conservation, les considérations théoriques et pratiques soutiennent que l'unité de conservation la plus importante est la population.

Mots-clés: Europe centrale, génétique des populations, phylogénétique, phylogéographie, écrevisses, salmonidés.

\section{INTRODUCTION}

\section{How important is genetics in conservation?}

There is little doubt that ecological issues, often in the framework of socio-economic pressures are the foremost concern in conservation, especially for freshwater ecosystems and their fauna. However, there are many conservation challenges that require, or benefit from the guidance and direction that either genetic data (directly) or genetic theory (indirectly) can provide. Geneticists play a significant role in the conservation planning of many endangered or heavily exploited species. This is especially true when captive breeding, stocking, or translocation programs are involved. There are as well, some conservation problems that are, at least in part, explicitly genetic in nature, such as those involving hybridisation and introgression of exotic or domesticated genomes into natural populations (ALLENDORF et al., 2001). More generally, indices of genetic diversity can be seen as simply another approach to assessing biodiversity. Biodiversity can be surveyed in terms of 1) Ecosystem diversity (most practical): whereby higher-level taxa or environmental variables are used; 2) Species diversity (most popular, and comprehendible to the public); or 3) Genetic diversity (most fundamental).

Many prominent conservation biologists promote an evolutionary perspective to conservation and thus a basic understanding of evolutionary genetics is essential. There are two basic biological principles that underscore the importance of genetics in conservation (adapted from MEFFE and CARROL, 1994). Foremost is the Fundamental Theorem of Natural Selection (FISHER, 1930), which states that the rate of evolutionary change is proportional to the amount of genetic diversity available. Thus, loss of genetic diversity lowers future evolutionary potential. Secondly is the well-established observation that "heterozygosity", a genetic diversity measure that can be applied to individuals or populations, is positively correlated to organismal fitness. Genetic diversity confers direct advantages to an organism's ability to survive and reproduce. A third principle relates to future human needs and interests. The global pool of genetic diversity in terms of coding genes represents a nearly unlimited source of irreplaceable information that may be harvested or managed to aid in our own survival. The long-term sustainability of our agricultural systems, for example, may in part rest on our ability to both preserve and manipulate genetic information.

The science of applying genetic approaches to conservation has emerged into a discipline known as "Conservation Genetics". This manuscript outlines the field by describing the range of methodologies available, their theoretical basis, and their suitability for addressing various questions in conservation biology. Emphasis is placed on providing examples from freshwater systems, pointing out their unique properties that influence the observed patterns and sustainability of genetic diversity.

\section{What is Conservation Genetics?}

The field of Conservation Biology investigates organisms that have been affected by habitat loss, exploitation or environmental change. Conservation Genetics is simply 
"Conservation Biology + Genetics". There are two primary and often complimentary approaches to conservation genetic research. The first is based on population genetic theory, and relates to the maintenance of genetic variability at the individual and population level. The second relates to the description of biodiversity and the systematic recognition of "units" of conservation, which may be species, subspecies, or molecularly defined lineages within a species. This second approach is based primarily on phylogenetic principles as well as phylogeography, which is seen as a bridge between population genetics and phylogenetics (AVISE, 2000).

Even among practitioners of the field, some may specialize in population genetic approaches with little appreciation for phylogenetics or phylogeography, or vice versa. For non-practitioners, the literature may seem to contain a bewildering array of techniques, analytical tools, jargon, and inference frameworks. It is unrealistic to expect that everyone involved in conservation be comprehensively educated in genetics, but it is equally undesirable and unnecessary for the non-geneticist to take the stand that we must "do" or "look at" the genetics of a particular organism without recognizing that there are highly differing approaches for each question of interest. As in all scientific endeavours, the clarity and meaningfulness of one's results is directly related to the clarity of one's initial question - Green's First Principle ${ }^{1}$ (GREEN, 1979). Conservationists should at least try to understand the scope of questions that a geneticist can work on, the potential for obtaining a meaningful answer, and very roughly, the appropriate techniques applied to various categories of inquiry.

\section{TWO APPROACHES TWO CONSERVATION GENETICS}

\section{Population genetics and the maintenance of genetic variability}

\section{Theory}

The basic problem linking genetics to conservation is that small populations, whether in the wild or in captivity, tend to lose genetic variation over time. Loss of genetic variation may increase the probability of population extinction or reduce opportunities for future adaptation to environmental changes. The primary mechanism responsible for the loss of variation in finite populations is random genetic drift, an evolutionary force that increases with decreasing population size. Genetic drift results from the fact that a population reproduces itself by sampling a small number of alleles (variants of a gene) produced by a limited number of individuals. Only an "infinitely" large population experiences no genetic drift.

Appreciation of this concept can be gained by grasping the enormous potential of genetic variation. Most characteristics of an organism are influenced by multiple genes. If we simply consider that each genetic locus has two alleles (genetic variants of a gene) in the population we can see how many unique combinations of alleles exist for $n$ loci: $2^{n}=$ the number of possible gametes and $3^{n}=$ the number of possible genotypes (Table I).

Quantitative traits such as body size or fecundity may be affected by 100 's of loci. If we just consider a moderate number of loci, like 20, we can see that the number of possible unique combinations of alleles for a single quantitative trait exceeds 10 billion, or more than the number of individuals existing for any species on earth! Thus, for finite populations, the number of genotypes actually produced each generation is just a very small sample of the theoretical possibilities. This is the essence of genetic drift, changes

\footnotetext{
1 Be able to state concisely to someone else what question you are asking. Your results will be as coherent and as comprehensible as your initial conception of the problem.
} 
in gene frequencies resulting simply from chance "sampling" events. Following this logic, it should be clear why each individual organism is genetically unique, and how two populations (especially if they are isolated) will quickly "drift" away from each other, in terms of allele frequencies.

\section{Table I}

The theoretical number of multi-locus genotypes (based on a number of gametes) in an infinite population, for $1,5,10$, and 20 loci.

\section{Tableau I}

Nombre théorique de génotypes multi-locus (basé sur le nombre de gamètes) dans une population infinie, pour 1, 5, 10 et 20 loci.

\begin{tabular}{cll} 
Loci & Genotypes & Gametes \\
\hline 1 & 3 & 2 \\
5 & 243 & 32 \\
10 & 59,049 & 1,024 \\
20 & $3.5 \times 10^{9}$ & $1.0 \times 10^{6}$ \\
\hline
\end{tabular}

The relation between genetic drift and population size is linked to the conservationist tenet that extinction risk increases with decreasing population size. In small populations, stochastic factors (disease, environmental perturbations, further habitat destruction, etc.) become more prevalent than deterministic processes (such as natural selection). By definition, genetic drift is stochastic. Drift can be countered by either mutation (creation of new genetic variation) or migration (addition of variation from neighbouring populations). Furthermore, the beneficial interaction between natural selection and mutation is enhanced by population size. The smaller a population, the more likely that genetic drift predominates over natural selection as an active evolutionary force. As habitat destruction leads to the creation of small, isolated populations, genetic drift increases, migration from neighbouring populations decreases, and the effectiveness of natural selection decreases.

Population geneticists view genetic diversity at different levels. The most fundamental level can be estimated with "heterozygosity", a measure that can be made at one or more loci within individuals, or averaged over individuals of entire population. Heterozygosity can only be measured at loci exhibiting bi-parental inheritance (one copy of the gene from each parent). The genetic locus must be polymorphic in the population, that is, it must exist as at least two different variants (or alleles). If the two copies of an inherited gene are identical (the same "allele") then the individual is said to be homozygous at that locus; if they are different, the individual is heterozygous. If a population has a high frequency of one allele, and a low frequency of another (and there are only two alleles), then there will be a low frequency of heterozygotes at that locus in the population. If two parents are closely related, there will be a lower frequency of heterozygous loci across the genome in the offspring. Thus, heterozygosity serves both as an estimate of overall genetic diversity within a population, and the level of inbreeding for both individuals and the population as a whole.

The fitness benefits of maintaining genetic variation are often noted, in theory. However, it is the negative effects of inbreeding that are best documented through our experience with domesticated or captive populations (e.g. agricultural plants and farm and zoo animals). In wild populations, a strong correlation between heterozygosity and fitness traits is not always evident. There is as well no standard measure for "insufficient" heterozygosity. Every organism has its unique demographic history and mating structure, which directly effects heterozygosity. What is clear is that artificially reduced levels 
of heterozygosity can cause problems. In my lecture, I gave three examples (cited from MEFFE and CARROL, 1994) involving freshwater organisms. One was a positive correlation between the number of heterozygous loci and shell length in the coot clam, Multinia lateralis; a second was the positive correlation between heterozygous loci and metabolic efficiency in the American oyster, Crassostrea virginica; and the third was the negative correlation between heterozygous loci and the number of asymmetric meristic characters in rainbow trout Oncorhynchus mykiss.

In conservation genetics, measures of inbreeding are directly related to population size. This is not the biological (census) population size $(N)$ that ecologists perceive, but rather the "effective population size" $\left(N_{\mathrm{e}}\right)$. The effective population size is a complex term as it is affected by sex ratio, demographic history, and variance in reproductive success. However, for our purposes it can be simply thought of as the effective number of breeding animals in a population, a number that is almost always considerably less than the census size in wild populations. With the cautionary note that any generalities in conservation may be dangerous, early practitioners of conservation genetics promoted the so-called "50/500" rule for maintaining genetic diversity (SOULE, 1980, FRANKLIN, 1980). So formulated, a founding population with an effective size of 50 (i.e. 25 males and 25 females) is seen as the minimum to avoid inbreeding depression (relates to a $1 \%$ change in the inbreeding coefficient) whereas a effective size of 500 in the wild is seen as necessary for the long-term maintenance of genetic variability (NELSON and SOULE, 1987). When pedigree information is available, a breeding protocol can be robustly calculated to minimize inbreeding depression. However, lacking such data, managers are left with such "rules of thumb", which some researchers find disturbing. For example, based on the extreme variation in reproductive success seen in salmonid fishes, ALLENDORF and RYMAN (1987) recommended a minimum of 100 males and 100 females (i.e. $N_{\mathrm{e}}$ of 200) to start a hatchery population, and population sizes in the wild of 5 or 10,000 may be necessary for maintaining genetic variation in the wild. However, critics assert that endangered mammals or birds are not necessarily doomed to extinction just because there are less than 500 individuals (MEFFE and CARROL, 1994) and some natural populations are known to have extremely low effective population sizes based on observed heterozygosity (such as the cheetah) but display no anomalous effects. While exceptions to every quantitative rule can be found, managers need some guidelines, and the $50 / 500$ rule still remains as potentially viable, based on simple genetic models.

For small fragmented populations of freshwater organisms, such as the scenario for many crayfish species, the perspective of maintaining effective population sizes of thousands of individuals appears to be fantasy. However, one must recognize what constitutes a population for conservation purposes. Small fragmented populations can be linked to each other in what is called a metapopulation (HANSKI and SIMBERLOFF, 1997). The exchange of a single individual between two fragmented populations over the course of a generation may be sufficient at maintaining equal gene frequencies between them (WANG, 2004). For a crayfish species limited to the uppermost reaches of small streams, it may be more practical to think of networks of neighbouring localities as the population of interest. In such a scenario, it may be more important to invest in the maintenance of colonization or dispersal corridors between small populations, than to simply build up or maintain the size of single populations. Additionally, a metapopulation perspective tries to differentiate between potential "source" and "sink" populations, which are not necessarily obvious (DIAS, 1996). Extremely small populations of crayfish, even when found in optimal habitat at high densities, most probably have a high extinction risk due to stochastic demographic events. As such these might be considered "sink" populations. The source for colonization of such habitats might be some habitat that provides the most stable conditions for long-term survival, independent of density. Source populations are not necessarily found in what is considered typical or optimal habitats. For example, a source for a particular headwater specific crayfish species could be in a lake or larger river, where 
the species exists only in very low densities, but stable over time. This is just a hypothetical example; the real nature of metapopulation dynamics in each species can only be resolved with long-term ecological research. Only relatively high-resolution population genetic data can confirm if a group of populations are linked, by contemporary gene flow.

Managers of highly fragmented species (such as headwater salmonid fishes or crayfish) may be tempted to "mix" individuals from different populations to avoid inbreeding. However, the inverse concept of inbreeding depression is outbreeding depression, a real concern for highly managed and endangered species. There are two main causes of outbreeding depression: coadaptation and local adaptation. Coadaptation results when a genome has achieved some internal balance with respect to fitness (co-adapted gene complexes, or a differentiated karyotype). Mixing individuals with different chromosome arrangements, for example, would result in genetic incompatibility, or may disrupt complexes of co-adapted genes. A second cause is local adaptation. Many species exist across variable habitats, and populations may have local adaptations. While the theoretical basis for such phenomena is strong, it is extremely difficult or impossible to determine where the borders between potential inbreeding and outbreeding depression exist for most organisms in the wild, and thus management decisions especially for highly endangered species are not easy. Many such decisions must be made with incomplete scientific knowledge.

\section{Quantitative genetics and the maintenance of phenotypic variability}

Most conservationists more easily relate to the phenotype of an organism, rather than genetic description. Popular perspectives as well, best relate to specific description of species, or unique phenotypic variants of a species. However, the genetic markers used for standard population genetic assessment, as described above, are almost never directly related to the phenotypic characters of an organism. This is sometimes seen as a paradox to the non-geneticist. However, most standard analyses in population genetics are based on the use of "neutral" genetic variation. In fact, most markers do not even code for any gene, and when they do, it is often hoped that the variation found does not have any adaptive significance.

Understanding the genetic basis for phenotypic characters of adaptive significance is a major focus of contemporary evolutionary biology, and this arena is being gradually extended into the field of conservation genetics (MORAN, 2002) But locating the genes corresponding to specific characters is simply not practical for the vast number of species that we are interested in. Moreover, the overwhelming majority of all phenotypic characters are not the result of single genes but rather multiple genes interacting with both each other and the environment. Quantitative genetics is the field addressing these issues, but a great deal of basic research is needed on a specific organism before candidate genes can be linked to phenotypic characters. Thus, such work is primarily limited to model organisms or species for which a great deal of funding is available (e.g. agricultural species). Nonetheless, the integration of phenotypic data into conservation genetic work can be useful and practical through the use of simple correlative statistics, as my own research with Arctic grayling demonstrates (FROUFE et al., 2003). The use of phenotypic data together with a population genetic approach is the only sure way to understand if specific phenotypic variants of a species within a region correspond to reproductively isolated systematic units. This can be done without knowing the genetic basis of the phenotype, and answers the question most relevant to the conservationist, as such reproductively isolated units demand distinct management and protection regimes.

\section{Practice}

The hallmark of a population genetic approach is its quantitative nature, and the necessity of sampling multiple genetic loci in multiple individuals per population. Like in any statistical problem, the number of loci or individuals required depends on the resolution and 
confidence desired to answer a particular question and the amount of existing variation in the sample populations. Nonetheless, typical population genetic surveys contain 8-20 genetic loci and 30 to 40 individuals per population. Up until the mid 1980's or so, population genetics was dominated by the use of starch gel electrophoresis and the detection of allelic variants (allozymes) at various protein coding loci (UTTER et al., 1987). Allozyme screening is still done today though the overall popularity of the methodology is diminishing. Currently, population genetics is being dominated by more direct screening of DNA variation, and especially by the use of highly variable repeat motifs, such as di-nucleotide microsatellites (GOLDSTEIN and SCHLÖTTERER, 1999) and more recently amplified fragment length polymorphisms (AFLP's)(CAMBELL et al., 2003). Regardless of the type of marker used, DNA based approaches have a major advantage over traditional allozyme screening as one can obtain sufficient DNA from non-lethal sampling of the organism (hairs, feathers, blood, saliva, minute tissue samples, etc.). Moreover, the high mutation rate of some types of genetic markers allows a level of resolution that was not previously possible. Using such highly variable genetic markers, many studies of wild populations have been carried out with as few as 5 to 6 loci. Dependant on the species, loci, and specific evolutionary circumstances, some simple questions can be addressed with low numbers of highly variable loci. Additionally, specific questions such as the presence of F1 hybrid individuals could be answered with a single diagnostic locus if the reliability of the approach has been established in a previous more comprehensive sampling program.

If the organism of interest has not been previously investigated with adequate markers for a population genetic approach, there is some time and cost involved to get started. However, this start-up cost is decreasing, and highly competent labs can begin to screen populations after only a few months of initial work and several thousand euros in costs (e.g. to isolate and optimise the use of new microsatellite loci). Here we provide a brief list of potential questions that might arise in a conservation program, and could be answered with a population genetic approach:

Do the individuals of a species, occurring at different nearby sites belong to one, or more interbreeding populations?

Does a particular population show signs of reduced genetic variation, compared to other populations?

Do individuals in a population show signs of introgression from a foreign source, or introduced species?

Do the animals in a breeding program reflect the level genetic variation found in healthy populations in the wild?

Is a breeding program able to maintain the variation it started with, or is genetic loss (through improper numbers, or artificial selection) occurring within the breeding program?

Do individuals expressing a particular rare phenotype belong to a reproductively isolated unit, or is this phenotype simply a polymorphic trait in the population?

These questions are typically answered by sampling multiple loci in multiple individuals, in an attempt to estimate genetic variation at the population level. Such questions are seldom or never properly addressed using, for example, sequences of a mtDNA gene, an approach more typical for systematic level questions.

\section{Systematics and the definition of conservation units}

\section{Theory}

The recognition of major components of intraspecific diversity within a species, and assigning them some form of conservation priority, has become extremely popular 
worldwide, across many taxonomic groups. Such units are often referred to as "Evolutionary Significant Units", or ESU's (RYDER, 1986). It is very important to recognize that there is no firm scientific basis for identifying meaningful units within a species, and the original conception of this practice developed within the framework of specific legislation, "The Endangered Species Act" within the U.S.A. As such, both the criteria for naming such units, and the usefulness of doing so should be, at least in part, rooted in the accompanying socio-economic and legislative framework in which such units can be granted some symbol of protection. Nonetheless, conservation geneticists have strived to develop some theoretically sound principles for naming conservation units.

Systematic approaches to defining conservation units are primarily rooted in the fields of phylogenetics and phylogeography, as opposed to population genetics. Phylogenetics principly deals with understanding the relationships among species or higher taxa, and thus the application of these disciplines to naming conservation units within a species is relatively new. This application first evolved based on the use of mitochondrial DNA gene sequences, or gene fragment analysis in quantifying intraspecific diversity (AVISE, 1994). In animals, mtDNA is most often inherited in a "clonal" fashion (i.e. without recombination) through the maternal line. Thus, simple sequences, or gene fragment patterns can be directly interpreted as haplotypes, and these haplotypes can be related using a simple "bi-furcating" tree, identical to what is often depicted for a species tree. Alternatively, haplotypes can be arranged into a multi-furcating network, using a variety of different algorithms, but also, for simple data sets, by hand. The practice of viewing such genealogical networks in terms of their geographic distribution has quickly grown into a subdiscipline "phylogeography". If particular molecular lineages of an organism correspond to specific geographic regions, the organism is said to have strong phylogeographic structure. For aquatic organisms, such structure is often, but not always, closely aligned to specific watershed patterns. It is extremely important to understand that the resolution of such structure is highly dependant on the gene that has been analysed. Different genes, whether from the mitochondrial or nuclear genome, have highly differing rates and patterns of evolution, and these differences are further greatly influenced by the taxonomic group (e.g. FROUFE et al., 2005). The ability to reveal phylogeographic structure is thus specific to each gene and taxonomic group, as well as the demographic history of the populations under study.

The most popular method of identifying units of conservation rests on constructing simple phylogenetic trees of single gene sequences (most often mitochondrial DNA) and looking for divergent clades that correspond to particular geographic regions (i.e. they have phylogeographic structure), or less often phenotypic variants. Several major caveats to this approach exist, however. First, the history of the mitochondrial genome may not effectively represent the history of populations in time or space, especially when there is sex-biased dispersal (e.g. male dispersal and female site fidelity). Second, there are an increasing number of examples where one species possesses the mtDNA lineage of another species, due to a form of introgressive hybridisation that leads to the phenomena of "mtDNA capture" (e.g BERNATCHEZ et al., 1995; LUDWIG et al., 2003). More simply, patterns revealed by the mtDNA molecule do not always relate to the evolutionary history of populations. Nonetheless, disregarding the more problematic issues raised above, large-scale phylogeographic structure is most easily analysed using mtDNA sequence data. One approach, or criteria, for defining conservation units based on such data, is that clades (representing geographic areas) be reciprocally monophyletic (MORITZ, 1994a, b). The point is that reciprocal monophyly between two lineages represents a relatively deep historical event, often corresponding to 100,000's or several million years of isolation. Theoretical expectations hold that populations isolated for such a long time bear numerous cryptic differences of evolutionary importance in their genomes. As these differences have accumulated over long time periods, it is doubtful that they can be replaced, and as such are of high conservation priority. Herein lies a bit of a controversy, however. Genetic 
variation can be viewed in terms of two axes, one corresponding to such historical isolation, and the other corresponding to adaptive divergence, as seen in the phenotype. A phenotypic character, such as a colour variant, can involve a single gene, and may be, under certain circumstances a replaceable evolutionary event. But, we are more certain of phenotypic differences, and under many circumstances the adaptive significance of such differences can be tested, or at least inferred through correlative research, and thus from a practical standpoint some feel that this "type" of variation should be the conservation goal. This controversy, can very easily have practical consequences especially when "conservation units" are to be named and managed, based on one, rather than the other type of genetic variation. In an evolutionary sense, there is no real dichotomy, as we view these two axes of variation schematically (Figure 1). Clearly, speciation can and does occur along either axis, at any point in time, though the likelihood of speciation increases with an increase in either phenotypic difference, or historical isolation, and both occur simultaneously in the same population. Regardless of one's perspective, everyone agrees that preserving an entire species is of much higher priority than specific lineages within a species. Not surprisingly, another approach, applying a more liberal species concept, would see any diagnosable lineage as a distinct species, eliminating the need to define conservation units within species (CRACRAFT et al., 1997; KOTTELAT, 1997; GOLDSTEIN et al., 2000).

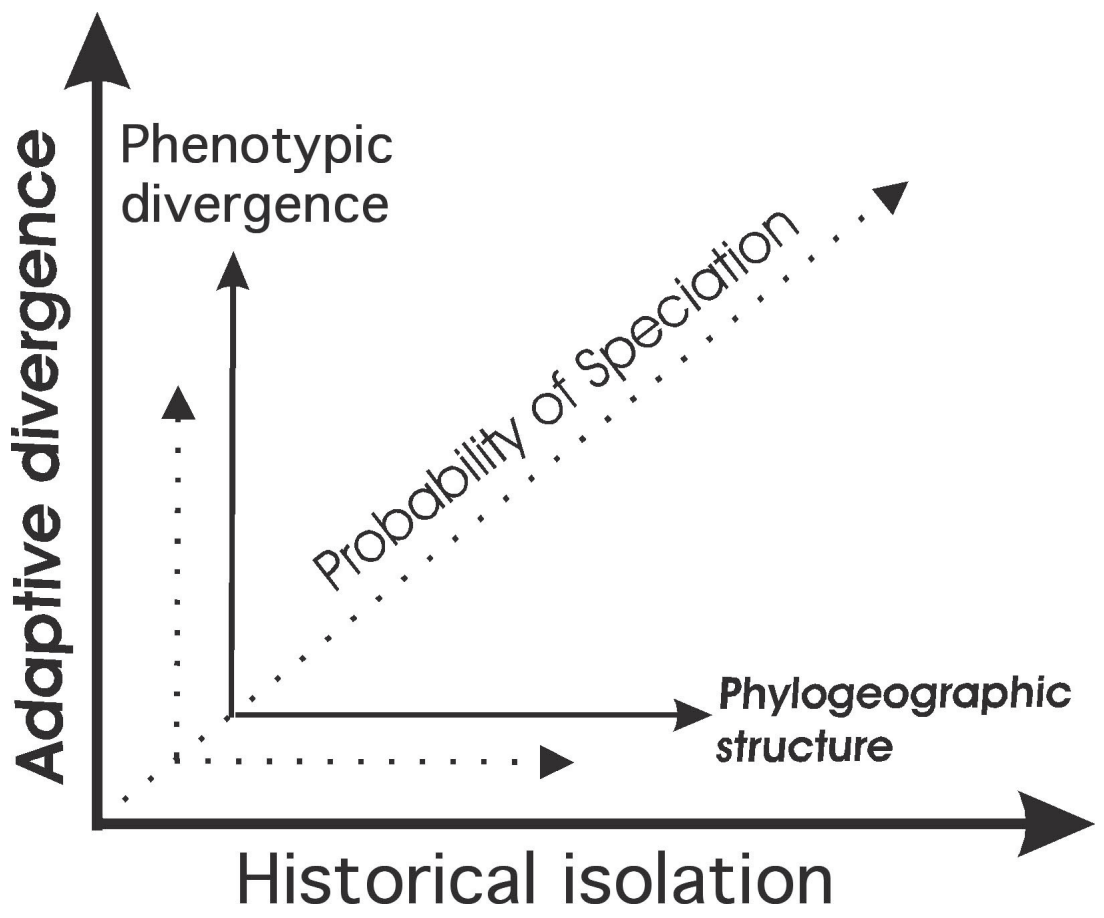

\section{Figure 1}

A schematic diagram depicting two axes of genetic variation, emphasizing that the probability of speciation increases along either axis, and the processes are not independant (modified from MORITZ, 1999 and MORITZ et al., 2002).

Figure 1

Diagramme présentant les deux axes de variation génétique, soulignant que la probabilité de spéciation augmente le long de chaque axe et que les processus ne sont pas indépendants (modifié d'après MORITZ, 1999 et MORITZ et al., 2002). 


\section{Practice}

Lacking a clear theoretical foundation, it is no wonder that the naming of conservation units in practice lacks rigid guidelines, beyond the suggestion of using reciprocally monophyletic clades in a phylogenetic tree. This criterion is not easily fulfilled, as many phenotypically distinct lineages, or even lineages shown to be reproductively isolated based on nuclear DNA markers, might not have reached the stage of reciprocal monophyly for a particular gene. Thus, more liberal criteria are often applied. As any two populations can be shown to genetically differ, it rests upon the researcher's level of motivation and investment in numbers of loci to demonstrate genetic differences, and argue for some unique conservation status. This practice, however, should be discouraged. More conservative practitioners have argued that the basic approach of displaying strong phylgeographic structure could be used as a starting framework, and then rare phenotypes within major historically isolated lineages could be given further protection (BERNATCHEZ, 1995). Others emphasize the protection of unique habitats, to which the adaptive potential of the organism responds, as the more practical approach to preserving phenotypic variation (MORITZ, 1999). My own addition to this controversy is to emphasize the socioeconomic and legislative potential (or constraints) to protect such units or habitats, and to use this framework to its maximum potential in protecting as many unique populations as possible. In thinking of the population (or meta-population) the conservation geneticist is on the firmest theoretical ground. The population, and not the species, or sub-specific lineage, is the unit of evolution, and in most cases (ignoring strong endangered species legislation) is as well the unit that can be managed or most effectively protected by man. I have put this argument forth, in recognition of the complex evolutionary history of one freshwater organism, the brown trout Salmo trutta, who's distribution of genetic variation does not strictly follow major drainage basins, nor do their obvious units of phenotypic variants correspond well to major mtDNA lineages (ANTUNES et al., 2001). Herein it is argued that, for freshwater organisms with numerous small fragmented populations, such a non-hierarchical distribution of genetic variation of adaptive significance should be the norm. While future research is needed to demonstrate if some crayfish species fulfil this expectation, little or no-harm can be done by trying to avoid the application of large-scale conservation units, and concentrate on the definition of populations, or metapopulations, as well as the protection of colonization corridors and unique habitats.

\section{Regional considerations on freshwater organisms (Central Europe).}

There are two important considerations concerning the uniqueness of studying freshwater organisms in central Europe, including the central Alpine region. First, the region is complex in terms of the paleohydrological dynamics that have continuously reshaped river drainage patterns during the climatic oscillations of the Pleistocene. This means that many organisms display complex phylogeographic structure with respect to current drainage patterns (e.g. ŠLECHTOVA et al., 2004, GUM et al., 2005). While this makes the region zoogeographically interesting, it also can cause some problems in trying to distinguish between natural and human-related mechanisms responsible for the distribution of genetic variation within and among river systems (WEISS et al., 2001, 2002a, b). Regardless of the regional constraint of the study, broad geographic sampling may be necessary to help define what constitutes native, as opposed to introduced lineages. The second concern, related to this native/introduced dilemma, is the extraordinary degree of anthropogenic influence directly related to the translocation of organisms from one river drainage to another. These translocations have been going on for half a millennium for some salmonid fishes (WEISS et al., 2001) or even into Roman, or pre-Roman ages for the common carp Cyprinus carpio (FROUFE et al., 2002). Such translocations need not necessarily confound inferences built on genetic data, provided they are taken adequately into account, and broad geographic sampling can support some picture of what may have been the "natural" distribution of native lineages. The use of mtDNA gene sequences, and 
the phylogeographic approach, is most helpful for ascertaining these patterns, precisely because of the lack of recombination and clonal inheritance pattern of the molecule. Thus, while populations may be comprised of an admixture of distant lineages, individuals still bear the genetic signature of their maternal lineage, for example.

Conservation management within such a cultural landscape as Central Europe, and potentially involving a mosaic of purely native and admixed populations presents unique challenges. Nonetheless, incorporation of basic genetic theory is important, and moreover, an appreciation of basic evolutionary forces, which for the most part are still functional in a population, regardless of its ancestral origin. For fragmented populations of freshwater organisms, it is additionally important to understand the role of the heterogeneous environment in adaptation, and thus to manage populations with the least amount of interference from translocations and/or artificially bred organisms as possible, regardless of whether or not they reveal a history of introduction (WEISS, 2004a, b). When artificial breeding and translocations become necessary, the first approaches should be as conservative as possible.

\section{REFERENCES}

ALLENDORF F.W., RYMAN N., 1987. Genetic management of hatchery stocks. In: Population Genetics and Fishery Management (RYMAN N. and UTTER F., eds.). University of Washington Press, Seattle and London, pp. 141-159.

ALLENDORF F.W., LEARY R.F., SPRUELL P., WENBURG J.K., 2001. The problems with hybrids: setting conservation guidelines. Trends in Ecology and Evolution, 16, 613622.

ANTUNES A., FARIA R., WEISS S., AND ALEXANDRINO P., 2001. Complex evolutionary history in the brown trout: insights on the recognition of conservation units Conservation Genetics 2, 337-347.

AVISE J.C., 1994. Molecular Markers, Natural History and Evolution. Chapman and Hall, New York, NY.

AVISE J.C., 2000. Phylogeography. The History and Formation of Species. Cambridge, Mass. Harvard Universtiy Press, 447 p.

BERNATCHEZ L., 1995. The role for molecular systematics in defining Evolutionary Signficant Units in fishes. In: J.L. NIELSON (Ed.), Evolution and the Aquatic Ecosystem: Defining Unique Units in Population Conservation. Bethesda, Maryland: American Fisheries Society, 114-132.

BERNATCHEZ L., GLEMET H., WILSON C.C., DANZMANN R.G., 1995. Introgression and fixation of Arctic char (Salvelinus alpinus) mitochondrial genome in an allopatric population of brook trout (Salvelinus fontinalis). Canadian Journal of Fisheries and Aquatic Sciences, 52, 179-185.

CAMBELL D., DUCHESNE P., BERNATCHEZ L., 2003. AFLP utility for population assignment studies: analytical investigation and empirical comparison with microsatellites. Molecular Ecology, 12, 1979-1991.

CRACRAFT J., 1997. Species concepts in systematics and conservation biology - an ornithological viewpoint. In: M.F. CLARIDGE, H.A. DAWAH and M.R. WILSON (Eds), Species: The Units of Biodiversity. London, Chapman and Hall, 325-339.

DIAS P.C., 1996. Sources and sinks in population biology. Trends in Ecology and Evolution, 11, 326-330.

FISHER R.A., 1930. The Genetical Theory of Natural Selection. Clarendon Press, Oxford. 
FRANKLIN I.R., 1980. Evolutionary change in small populations. In: M.E. SOULE and B.A. WILCOX (Eds), Conservation Biology: an Evolutionary-Ecological Perspective, Sinauer Associates, Sunderland, MA., 135-139.

FROUFE E., MAGYARY I., LEHOCZKY I., WEISS S., 2002. mtDNA sequence data supports an Asian ancestry and single introduction (or expansion) of the common carp (Cyprinus carpio) into the Danube basin. Journal of Fish Biology, 61, 301-304.

FROUFE E., KNIZHIN I., KOSKINEN M.T., PRIMMER C.R., WEISS S., 2003. Identification of reproductively isolated lineages of Amur gralying (Thymallus grubii Dybowski 1869): concordance between phenotypic and genetic variation. Molecular Ecology $12,2345-2355$.

FROUFE E., ALEKSEEV S., KNIZHIN I., WEISS S., 2005. Comparative mtDNA sequence (control region, ATPase 6 and NADH-1) divergence in Hucho taimen (Pallas, 1773) across four Siberian river basins. Journal of Fish Biology, in press.

GOLDSTEIN D. and SCHLÖTTERER C., 1999. Microsatellites. Evolution and applications. Oxford University Press, Oxford.

GOLDSTEIN P.Z., DE SALLE R., AMATO G. and VOGLER A.P., 2000. Conservation genetics at the species boundary. Conservation Biology,14, 120-131.

GUM B., GROSS R., KUEHN R., 2005. Mitochondrial and nuclear DNA phylogeography of European grayling (Thymallus thymallus): evidence for secondary contact zones in central Europe. Molecular Ecology, 14, 1707-1725.

GREEN R.H., 1979 Sampling design and statistical methods for environmental biologists. John Wiley and Sons, New York. 257 p.

HANSKI I., SIMBERLOFF D., 1997. The metapopulation approach, its history, conceptual domain and application to conservation. In: HANSKI I. and GILPIN M.E. (Eds). Metapopulation Biology: Ecology, Genetics and Evolution. Academic Press, London, 5-26.

KOTTELAT M., 1997. European freshwater fishes: An heuristic checklist of the freshwater fishes of Europe (exclusive of the former USSR), with an introduction for nonsystematic and comments on the nomenclature and conservation. Biologia 52, $1-271$.

LUDWIG A., CONGIU L., PITRA C., FICKEL J., GESSNER J., FONTANA F., PATARNELLO T., ZANE L., 2003. Nonconcordant evolutionary history of maternal and paternal lineages in Adriatic sturgeon. Molecular Ecology, 12, 3253-3264.

MEFFE G.K., CARROL R.C., 1994. Principles of Conservation Biology. Sinauer Associates, Inc. Sunderland Mass. $600 \mathrm{p}$.

MORAN P., 2002. Current conservation genetics: building an ecological approach to the synthesis of molecular and quantitative genetic methods. Ecology of Freshwater Fish, 11, 30-55.

MORITZ C., 1994a. Applications of mitochondrial DNA analysis on coservation: a critical review. Molecular Ecology, 3, 401-411.

MORITIZ C., 1994b. Defining "Evolutionary Significant Units" for conservation. Trends in Ecology and Evolution, 9, 373-375.

MORITZ C., 1999. Conservation units and translocations: Strategies for conserving evolutionary processes. Hereditas 130, 217-228.

MORTIZ C., MCGUIGAN K., BERNATCHEZ L., 2002. Conservation of freshwater fishes: integrating evolution and genetics with ecology. In: COLLARES-PEREIRA M.J., 
COELHO M.M. and COWX I.G. (eds) Conservation of Freshwater Fishes: Options for the Future, 293-310.

NELSON K., SOUL M.E., 1987. Genetical conservation of exploited fishes. In: RYMAN N. and UTTER F. (eds) Population Genetics and Fishery Management, 345-368.

RYDER O.A., 1986. Species conservation and systematics: the dilemma of subspecies. Trends in Ecology and Evolution, 1, 9-10.

ŠLECHTOVA' V., BOHLEN J., FREYHOF J., PERSAT H. and DELMASTROD G.B., 2004. The Alps as barrier to dispersal in cold-adapted freshwater fishes? Phylogeographic history and taxonomic status of the bullhead in the Adriatic freshwater drainage. Molecular Phylogenetics and Evolution, 33(1), 225-239.

SOULE M.E., 1980. Thresholds for survival: Maintaining fitness and evolutionary potential. In: M.E. SOULE and B.A. WILCOX (eds), Conservation Biology: an EvolutionaryEcological Perspective, pp. 151-169. Sinauer Associates, Sunderland, MA.

UTTER F., AEBERSOLD P., WINANS G., 1987. Interpreting genetic variation detected by electrophoresis. In: Population Genetics and Fishery Management (RYMAN N. and UTTER F., eds.). University of Washington Press, Seattle and London, 21-46.

WANG J., 2004. On the application of the one-migrant-per-generation rule to conservation and management. Conservation Biology 18, 332-343.

WEISS S., SCHLÖTTERER C., WAIDBACHER H., JUNGWIRTH M., 2001. Haplotype (mtDNA) diversity of brown trout Salmo trutta in tributaries of the Austrian Danube: massive introgression of Atlantic basin fish - by man or nature?. Molecular Ecology 10, 1241-1246.

WEISS S., UIBLEIN F., JAGSCH A., 2002a. Conservation of salmonid fishes in Austria: current status and future strategies. In: COLLARES-PEREIRA M.J., COELHO M.M. and COWX I.G. (eds) Conservation of Freshwater Fishes: Options for the Future, 72-78.

WEISS S., PERSAT H., EPPE R., SCHLÖTTERER C., UBLEIN F., 2002b. Complex patterns of colonization and refugia revealed for European grayling Thymallus thymallus, based on complete sequencing of the mtDNA control region. Molecular Ecology, 11, 1393-1407.

WEISS S., 2004a. Authochthon: Sein oder Nichtsein? Das Märchen von der österreichischen Bachforelle. Natur and Land (Zeitschrift des Naturschutzverbundes Österreich) 4, 20-21.

WEISS S., 2004b. Irrtum und Wahrheit zur "Urforelle". Salzburgs Fischerei (Offizieles Pressorgan des Landesfischereiverbandes Salzburg) 4, December, 22-23. 
